\title{
Pain Response of Healthy Workers Following a Functional Capacity Evaluation and Implications for Clinical Interpretation
}

\author{
Remko Soer · Johan W. Groothoff · Jan H. B. Geertzen - Cees P. van der Schans • \\ David D. Reesink · Michiel F. Reneman
}

Published online: 11 April 2008

(C) The Author(s) 2008

\begin{abstract}
Background and aim Functional Capacity Evaluations (FCEs) are used to quantify physical aspects of work capacity. Safety is a critical issue for clinical use of an FCE. Patients with Chronic Low Back Pain (CLBP) are known to report a temporary increase in pain following an FCE, but it is not known whether this increase is a normal pain response to FCE. It is currently unknown how healthy subjects respond to an FCE and whether this should be interpreted as a normal reaction after physical exercise. This study was performed to quantify the intensity, duration, location and nature of the pain response following an FCE in healthy subjects and to compare this pain response with the pain response of patients with CLBP from a previous study. Methods A total of 197 healthy working subjects between 20 and 60 years of age volunteered to
\end{abstract}

R. Soer $(\varangle)$ J. H. B. Geertzen · M. F. Reneman

Center for Rehabilitation, University Medical Center Groningen,

University of Groningen, P.O. Box 30.002, Haren 9750 RA,

The Netherlands

e-mail: r.soer@cvr.umcg.nl

R. Soer · J. W. Groothoff · J. H. B. Geertzen · M. F. Reneman Graduate School for Health Research, University Medical Center Groningen, University of Groningen, Groningen,

The Netherlands

J. W. Groothoff

Department of Health Sciences, University Medical Center

Groningen, Groningen, The Netherlands

C. P. van der Schans

University for Professional Education, Hanze Hogeschool

Groningen, Groningen, The Netherlands

D. D. Reesink

University Center Promotions Groningen, Groningen,

The Netherlands participate in this study. All subjects performed a 12-item FCE. Pain response was measured by a self-constructed Pain Response Questionnaire (PRQ). Descriptive statistics were used to describe the pain response following an FCE. Mann-Whitney and $t$-tests were performed to compare the data from this study with data of patients with CLBP from a previous study. Results About $82 \%$ of all subjects reported a pain response following the FCE. The intensity of the pain response after $24 \mathrm{~h}$ post FCE was a median of 3.0 on a numeric rating scale $(0-10)$. About $78 \%$ of all pain was reducible to muscle soreness. Pain was most often reported in the upper legs $(51 \%)$, the lower back $(38 \%)$ the shoulders (37\%) and upper arms (36\%). Symptoms decreased to pre-FCE levels in a mean of 3 days. The pain response of 2 subjects (1\%) lasted for 3 weeks. The intensity and duration of the pain response of healthy subjects was not significantly different from the response of patients with CLBP. Conclusion Pain response of $99 \%$ of all subjects who reported a pain response was interpreted as normal. It was concluded that a pain response following an FCE can be expected in healthy subjects and that this pain response is a normal musculoskeletal reaction. The pain response of patients with CLBP resembles the pain response of healthy subjects.

Keywords Functional assessment - Safety ·

Normative values · Muscle soreness - Pain response

\section{Introduction}

Functional Capacity Evaluations (FCEs) are sets of functional tests to measure the ability to perform work-related activities. FCEs are used in occupational rehabilitation, return to work determinations, disability determinations 
and medico-legal matters. Hart et al. [1] have suggested guidelines and demands for clinical use of FCE with regards to safety, reliability, validity, practicality and utility. Validity and reliability of FCE have been addressed, [2] but safety has scarcely been addressed so far. Five studies reported about the safety of FCE [3-7]. One study suggested that safety can be monitored in three main areas: physiological (heart rate and blood pressure), biomechanical (muscle fatigue or weakness) and psychophysical (pain or fear of re-injury) [3]. The outcome of this study was that the FCE could be administered safely when these safety issues are carefully taken into account and if the recommended guidelines, as provided by the US National Institute for Occupational Safety and Health (NIOSH) [8] are applied to minimize the risk of further or other injury [3]. The California Functional Capacity Protocol (Cal FCP) was found to be a safe protocol because no new injuries or exacerbations of current impairments were reported in a study sample of 64 patients suffering from soft tissue musculoskeletal injuries [4]. A study, in which the development of the EPIC Lift Capacity (ELC) test was described, reported this test to be safe based on 687 tests in healthy and disabled subjects because no incidents were reported. Several healthy subjects however reported nextday symptoms which were identified as soreness [5]. Others concluded that FCE appeared to be safe in patients with Chronic Low Back Pain (CLBP) because no injury reports had been filed and the pain decreased to pre FCE levels [6]. The study lacked normative data to compare the results to. It was suggested that further research should focus on operational definitions for injury, in order to test the safety of FCE. In a study in which FCE lifting results were compared with the NIOSH recommended safe weight lifting (RWL), it was observed that the RWL of the NIOSH and the FCE lifting results differed substantially [7]. It is unclear which outcome could be used as a RWL of safe lifting. Additional research into safety and operational definitions of injury are needed to test these contrary findings.

Safety in FCE is a key issue because kinesiophysical FCEs demand a patients' maximum physical effort [9]. A normal physical response during maximum physical effort includes an increase in heart rate, systolic blood pressure, body temperature, sweat secretion and breath frequency [10]. Besides this, delayed onset muscles soreness (DOMS) after intensive and uncommon exercising is a normal reaction of the musculoskeletal system [11]. It is currently not known how healthy workers respond to an FCE and therefore unknown what should be considered to be a normal pain response. Consequently, it is difficult to clinically interpret the pain increase in patients following an FCE. If the pain response in healthy subjects is known, a comparison can be made between the pain response of healthy subjects and the pain response of patients.

The objectives of this study were to quantify the location, intensity, duration and nature of the pain response in healthy subjects following a 12-item FCE. The second goal of this study was to explore differences and similarities between the data from this study and data from patient reports used in a previous study [6]. In the current study, an FCE was considered safe when the FCE does not lead to injuries and when the pain response is considered to be normal. According to the physiology literature, a pain response was considered normal when symptoms increased within the first $24 \mathrm{~h}$ following FCE, peaked between 24 and $72 \mathrm{~h}$ and subsided and disappeared within 5-7 days after the FCE [11]. Any response not following this definition was interpreted as an abnormal response.

\section{Methods}

Subjects

A total of 232 healthy adults working in a broad range of jobs voluntarily participated in this study. Subjects were recruited via local press and personal networks. Subjects were included after providing informed consent and signing a statement of good health, when meeting the criteria of the Physical Activity Readiness-Questionnaire (PAR-Q) $[12,13]$, and when they were between 20 and 60 years of age and worked at least $20 \mathrm{~h}$ per week for the last year. Excluded were subjects who had been absent from work for more than 2 weeks because of dysfunction of the musculoskeletal system during the year prior to FCE, or subjects whose blood pressure in rest exceeded $159 \mathrm{mmHg}$ (systolic) or $100 \mathrm{mmHg}$ (diastolic) [14].

\section{Procedures}

Prior to the FCE, subjects filled in a questionnaire to obtain demographic information, a Pain Response Questionnaire and the PAR-Q. Subjects performed a $2 \mathrm{~h}, 12$-item FCE (see Table 1). After an introduction to general FCE procedures, subjects were briefly instructed how to perform each individual test. Each test was first demonstrated by the evaluator. Subjects were allowed to start the next test when the heart rate (HR) was below $70 \%$ of the age related maximum HR (220-age). Subjects received instructions on how to use the Borg CR-10 scale which was used for measurement of perceived exertion after each test $[15,16]$. Subjects were individually evaluated by 1 of 15 physiotherapy students who had completed a 2-day FCE-training. This study was approved by the Medical Ethical 
Table 1 Content of the FCE

\begin{tabular}{|c|c|c|c|c|}
\hline & Test & Procedure & $\begin{array}{l}\text { Performance } \\
\text { category }\end{array}$ & References \\
\hline 1 & Lifting floor to table & $\begin{array}{l}5 \text { lifts of a weighted crate from table to floor v.v.; } 4-5 \text { weight increments } \\
\text { until maximum lifting capacity is reached; }<90 \text { s Maximum performance } \\
\text { was recorded }(\mathrm{kg}) \text {. }\end{array}$ & Strength & {$[17]$} \\
\hline 2 & Lifting table to crown height & $\begin{array}{l}5 \text { lifts from table to crown height v.v.; } 4-5 \text { weight increments until maximum } \\
\text { is reached; }<90 \mathrm{~s} \text { Maximum performance was recorded }(\mathrm{kg}) \text {. }\end{array}$ & Strength & {$[17,18]$} \\
\hline 3 & Long carry two handed & $\begin{array}{l}\text { Carry } 20 \mathrm{~m} \text {; waist height; } 4-5 \text { weight increments until maximum is reached; } \\
\quad<90 \text { s Maximum performance was recorded }(\mathrm{kg}) \text {. }\end{array}$ & Strength & {$[17]$} \\
\hline 4 & Overhead work test (loaded) & $\begin{array}{l}\text { Standing with hands at crown height; manipulating nut/bolts, wrists are } \\
\text { loaded with } 1 \mathrm{~kg} \text { cuff weight. Duration was recorded }(\mathrm{sec}) \text {. }\end{array}$ & $\begin{array}{l}\text { Postural } \\
\text { tolerance }\end{array}$ & [18] \\
\hline 5 & $\begin{array}{l}\text { Forward bend test standing } \\
\text { (loaded) }\end{array}$ & $\begin{array}{l}\text { Standing with } 30-60^{\circ} \text { trunk flexion; Manipulating nut/bolts, upper back is } \\
\text { loaded with a weight of } 5 \mathrm{~kg} \text {. Duration was recorded }(\mathrm{sec}) \text {. }\end{array}$ & $\begin{array}{l}\text { Postural } \\
\text { tolerance }\end{array}$ & [17] \\
\hline 6 & Dynamic bending test & $\begin{array}{l}\text { Fast repetitive bending at hips and back; remove small object from floor to } \\
\text { crown height; } 20 \text { reps. Time to complete } 20 \text { reps was recorded (sec). }\end{array}$ & Repetitive work & {$[17]$} \\
\hline 7 & Repetitive side reaching test & $\begin{array}{l}\text { Remove object horizontally at table height from right to left with right hand/ } \\
\text { arm and vice versa; distance: wing span; } 30 \text { reps.; sitting. Time to } \\
\text { complete } 30 \text { reps was recorded (sec). }\end{array}$ & Repetitive work & {$[17,18]$} \\
\hline 8 & Hand grip strength test & $\begin{array}{l}\text { In a seated position; the elbow flexed at } 90^{\circ} \text {; grip strength of the right and left } \\
\text { hand was measured in a three trial procedure; five different handgrip } \\
\text { positions. Mean performance was recorded (kgF). }\end{array}$ & Strength & {$[17,18]$} \\
\hline 9 & Finger strength test & $\begin{array}{l}\text { In a seated position; the elbow flexed at } 90^{\circ} \text {; tip, key and palmar pinch } \\
\text { strength of the fingers was measured in a three trial procedure; left/right. } \\
\text { Mean performance was recorded }(\mathrm{kgF}) \text {. }\end{array}$ & Strength & {$[17,18]$} \\
\hline 10 & Purdue pegboard task & $\begin{array}{l}\text { In a seated position; placing pins with one hand as fast as possible in a three } \\
\text { trial procedure; left/right. Mean number of pins per } 30 \mathrm{~s} \text { was recorded. }\end{array}$ & Coordination & {$[17,18]$} \\
\hline 11 & $\begin{array}{l}\text { Complete Minnesota } \\
\text { dexterity test }\end{array}$ & $\begin{array}{l}\text { In a seated position; displacing } 59 \text { blocks in a pre determined way with left } \\
\text { and right hand as fast as possible in a four trial procedure. Time to } \\
\text { complete } 4 \text { trials was recorded (sec). }\end{array}$ & Coordination & {$[17,18]$} \\
\hline 12 & Treadmill ergometry & $\begin{array}{l}\text { The subject walks/runs on a treadmill to } 85 \% \text { of HR max. At timed stages of } \\
\text { three minutes the speed and grade of slope of the treadmill are increased } \\
\text { (Bruce protocol). Time to reach } 85 \% \text { of } \mathrm{HR} \text { max was recorded and } \\
\text { transformed into VO2 max value }(\mathrm{ml} / \mathrm{min} / \mathrm{kg} \text { ). }\end{array}$ & Endurance & [19] \\
\hline
\end{tabular}

Committee of the University Medical Center Groningen, the Netherlands.

\section{Endpoints}

Tests could be terminated for three endpoints [3]: cardiac, biomechanical and subject endpoints. Cardiac endpoint was reached when HR was above $85 \%$ of age related maximum. HR was measured with a heart rate monitor. Biomechanical endpoints were: loss of solid standing basis during lifting tasks or loss of control of the load. Biomechanical endpoints were determined by the evaluators. Subject endpoints were reached when subjects stopped the test. Subjects were instructed to stop at any point if they wished to do so.

\section{Pain Response Questionnaire}

A Pain Response Questionnaire (PRQ; Appendix 1) was developed to obtain information about the pain response prior to FCE and 7 days following FCE, medication use following the FCE and to control for unusual or heavy physical activity in days following the FCE. The intensity of the pain response was measured by an 11-point numeric rating scale (NRS) for pain ranging from ' 0 ' (no pain) to ' 10 ' (worst pain imaginable) for 17 body parts separately [20]. Subjects were asked whether their pain score was reducible to muscle soreness, of a different origin, a combination of these, or whether the origin of pain was considered unknown. The PRQ was filled in by the subjects just prior to the FCE, directly following the FCE and was taken home to fill in for at least on three consecutive days after the FCE to a maximum of 7 days. Subjects were asked to fill in the PRQ on the days following the FCE after $13.00 \mathrm{~h}$. The PRQ could be returned in a reply-paid envelope if pain was no longer reported or when the maximum of 7 days had been reached. The PRQ was pilot tested in 14 healthy subjects [21] and was found suitable for testing. None of the 14 subjects reported a response longer than 7 days in this pilot study. 


\section{Data Analyses}

Descriptive statistics were used to describe the subject characteristics and pain response. Box plots were made because the data of pain intensity was not normally distributed. To be able to compare data of healthy subjects with data of patients with chronic low back pain from a previous study [6], independent samples Mann-Whitney and $t$-tests were performed. Results were considered statistically significant when $P<0.05$. A Bonferroni correction was applied to reduce type 1 error $(P=\alpha / n=0.006$ for significance $)$.

\section{Results}

A total of 35 subjects of the original group of 232 volunteers were excluded from analyses because they did not meet the inclusion criteria $(n=20)$, did not return the PRQ ( $n=8$ ) or because they resigned to participate after all $(n=7)$. Included were 197 subjects (102 males and 95 females), whose data were used for analyses. Subject characteristics are presented in Table 2.

\section{Pain Response}

A total of 162 subjects $(82 \%)$ reported a pain response following the FCE. 53 subjects reported pain prior to the
FCE and 57 subjects reported pain directly after the FCE. Descriptive statistics of the origin and intensity of the pain of the main body parts are presented in Table 3 . Because most subjects reported their maximum pain intensity on the first day following the FCE, Table 3 reflects the status $24 \mathrm{~h}$ following the FCE. Most often, a pain response was reported in the upper legs $(51 \%)$, the lower back (38\%) and the upper arm (37\%) and shoulders $(36 \%)$. The location of the pain response of the 17 main body regions is presented in Fig. 1. The intensity of the pain over time from pre FCE level to the next 7 days following the FCE is presented in Fig. 2. Figure 2 demonstrates that the highest pain

Table 2 Subject characteristics ( $n=197 ; 102$ men, 95 women)

Yrs = years; $\mathrm{cm}=$ centimeter; $\mathrm{kg}=$ kilogram

${ }^{\mathrm{a}}$ Low $=$ primary school unfinished and finished;

intermediate $=$ secondary

school and junior; college; high $=$ bachelor's degree and university

\begin{tabular}{lr}
\hline & Mean (SD) \\
\hline Age (yrs) & $40.8(10.5)$ \\
Body length (cm) & $176.4(9.4)$ \\
Body weight (kg) & $73.4(12.4)$ \\
Hours working & $34.9(8.2)$ \\
$\quad$ per week & \\
\hline Education $^{\mathrm{a}}$ & \\
\hline Low & 16 \\
Intermediate & 48 \\
High & 129 \\
Other & 4 \\
\hline
\end{tabular}

Table 3 Description of intensity, location and origin of pain for those subjects who reported pain $24 \mathrm{~h}$ following FCE ( $n=162)$

\begin{tabular}{|c|c|c|c|c|c|c|}
\hline \multirow[t]{2}{*}{ Location } & \multirow{2}{*}{$\begin{array}{l}\text { Pain response } \\
\%(n)\end{array}$} & \multirow{2}{*}{$\begin{array}{l}\text { Mean (SD) } \\
\text { pain intensity }\end{array}$} & \multicolumn{4}{|c|}{ Origin of pain (self report) } \\
\hline & & & DOMS \% (n) & Other \% $(n)$ & Both \% $(n)$ & Unknown $\%(n)$ \\
\hline Any location (max pain) & $82(162)$ & $3.0(2.4)$ & $\mathrm{n} / \mathrm{a}$ & $\mathrm{n} / \mathrm{a}$ & $\mathrm{n} / \mathrm{a}$ & $\mathrm{n} / \mathrm{a}$ \\
\hline Neck & $24(49)$ & $2.9(1.9)$ & $78(39)$ & $2(1)$ & $6(3)$ & $12(6)$ \\
\hline Shoulders & $36(73)$ & $3.1(1.7)$ & $80(58)$ & $1(1)$ & $6(4)$ & $14(10)$ \\
\hline Upper arm & $37(75)$ & $2.7(1.4)$ & $83(62)$ & $4(3)$ & $0(0)$ & $13(10)$ \\
\hline Elbow & $7(15)$ & $3.0(1.6)$ & $60(9)$ & $13(2)$ & $7(1)$ & $20(3)$ \\
\hline Lower arm & $12(25)$ & $2.4(1.6)$ & $84(21)$ & $0(0)$ & $0(0)$ & $16(4)$ \\
\hline Wrists & $4(9)$ & $2.4(1.2)$ & $56(5)$ & $33(3)$ & $0(0)$ & $11(1)$ \\
\hline Hand & $5(11)$ & $2.6(1.9)$ & $73(8)$ & $0(0)$ & $0(0)$ & $27(3)$ \\
\hline Chest & $1(2)$ & $5.0(1.4)$ & $100(2)$ & $0(0)$ & $0(0)$ & $0(0)$ \\
\hline Upper back & $19(39)$ & $3.4(2.0)$ & $92(36)$ & $0(0)$ & $3(1)$ & $5(2)$ \\
\hline Lower back & $38(77)$ & $3.6(2.0)$ & $81(62)$ & $7(5)$ & $4(3)$ & $9(7)$ \\
\hline Buttocks & $15(30)$ & $3.1(2.0)$ & $93(28)$ & $7(2)$ & $0(0)$ & $0(0)$ \\
\hline Belly & $3(6)$ & $2.3(1.7)$ & 67 (4) & $0(0)$ & $0(0)$ & $33(2)$ \\
\hline Upper leg & $51(103)$ & $3.3(1.9)$ & $88(91)$ & $2(2)$ & $1(1)$ & $9(9)$ \\
\hline Knee & $4(9)$ & $3.1(3.0)$ & $33(3)$ & $33(3)$ & $0(0)$ & $33(3)$ \\
\hline Lower leg & $12(25)$ & $2.1(1.2)$ & $88(22)$ & $8(2)$ & $0(0)$ & $4(1)$ \\
\hline Ankle & $2(4)$ & $2.0(0.8)$ & $75(3)$ & $0(0)$ & $0(0)$ & $25(1)$ \\
\hline Foot & $1(2)$ & $1.0(0.0)$ & $0(0)$ & $0(0)$ & $0(0)$ & $100(2)$ \\
\hline
\end{tabular}

$n$ : number of subjects reporting a response. $\mathrm{n} / \mathrm{a}$ : not applicable due to reports of pain responses on more than one body region. DOMS: Delayed Onset Muscle Soreness: Other: pain other than muscle soreness. Both: a combination of muscle soreness and other. Unknown: origin of pain is unknown 
Fig. 1 Location of the pain response expressed in percentage of subjects

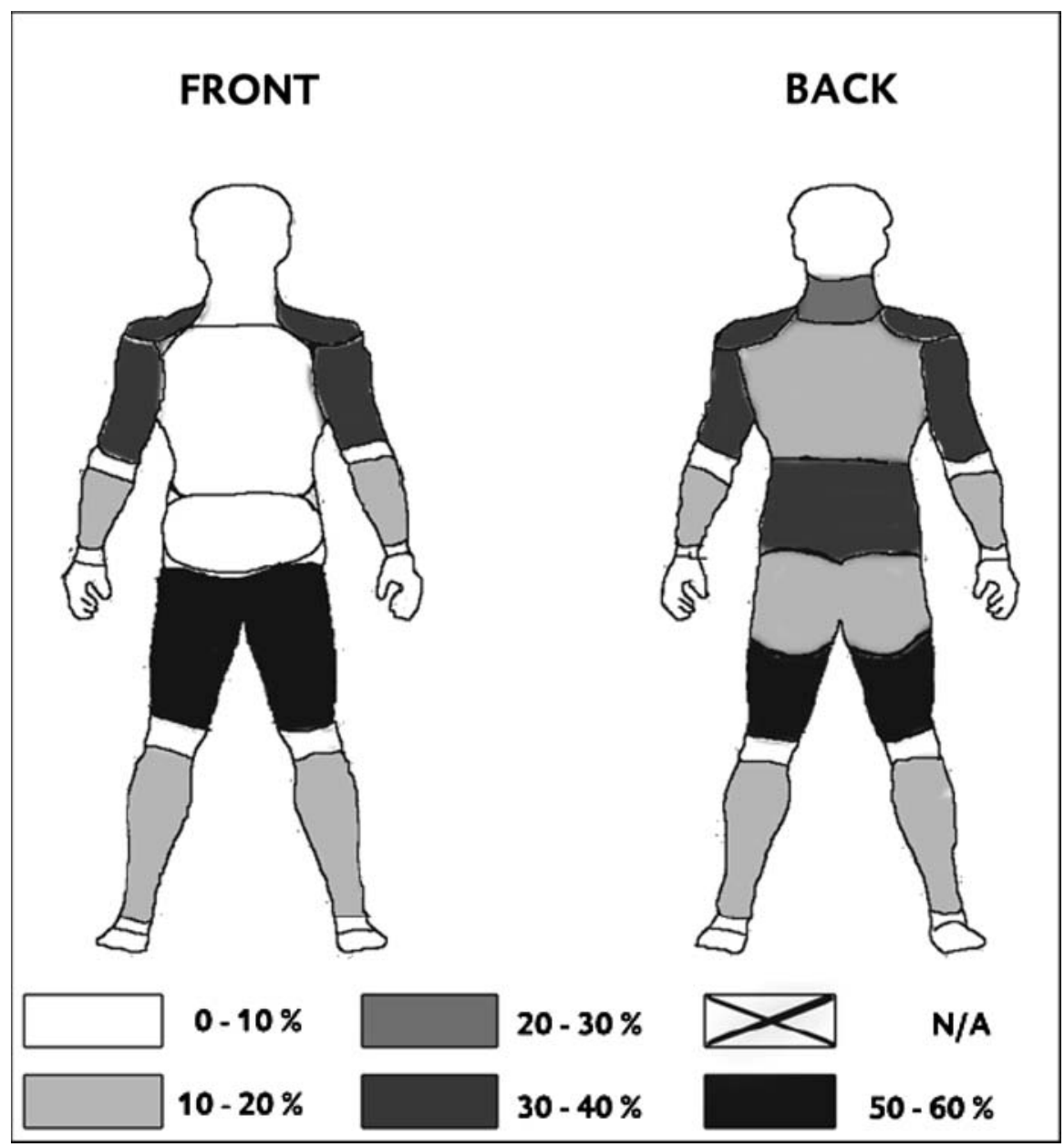

response occurred within $24 \mathrm{~h}$ following the FCE with a median pain intensity of 3 on a $0-10$ NRS. The pain had returned to pre-FCE levels 3 days post FCE. A total of 35 subjects $(18 \%)$ reported a pain intensity over $2.5 \times$ the interquartile range (IQR) above the median (Fig. 2) which was not expected in a population with a normal distribution. Additional analyses were performed to explore whether different individual health related characteristics could be identified to explain a high pain response. Results are presented in Table 4. A total of 35 subjects reported a value over $2.5 \mathrm{x}$ IQR above the median on pain intensity. This group scores lower on vitality, general health perception and social functioning. A pain response lasting longer than 7 days was reported by 2 subjects (1\%). One subject reported low back pain which lasted for 22 days. After a medical consultation of an independent physician by telephone it was concluded that these symptoms were non-specific of origin. After 22 days the person involved had fully recovered. The other subject was diagnosed with a 'trigger-finger'. These complaints lasted for 21 days until full recovery. All other values over $2.5 \times \mathrm{IQR}$ above the median had recovered to pre-FCE level within 7 days following FCE. Four subjects reported to have used nonsteroidal non-prescriptive pain medication following the FCE. One subject used a homeopathic ointment. All of these subjects had stopped their medication use 3 days following FCE. One subject has used a massage as a means of coping with post FCE pain response.

\section{Comparison with Patients with CLBP}

Table 5 lists the descriptives of former research in patients with CLBP [6] being compared to the data of healthy subjects in the current study. To enable comparison of both datasets on pain intensity, scores from the PRQ were transformed to a 3-point scale (pain decrease, no difference, pain increase). No significant differences in pain increase were found between healthy subjects and patients with CLBP (Table 5). Independent $t$-tests show that differences in the duration of the pain response between patients with CLBP and healthy subjects were not significant (Table 5). 
Fig. 2 Boxplots of the median concerning the reported pain response per day. Bold horizontal lines: medians. Gray boxes: interquartile range (+ and $-25 \%$ of median). Vertical tick marks: $1.5 \times$ interquartile range. Stars: value over $2.5 \times$ IQR above the median. Numbers: number of subjects

Table 4 Descriptives of RAND-36 and $t$-tests of differences on the RAND-36 between subgroups 1 and 2

Subgroup 1: subjects reporting pain intensity less than

$2.5 \times \mathrm{IQR}$. Subgroup 2:

Subjects reporting over

$2.5 \times \mathrm{IQR}$ above the median pain intensity

SD: standard deviation; IQR: interquartile range

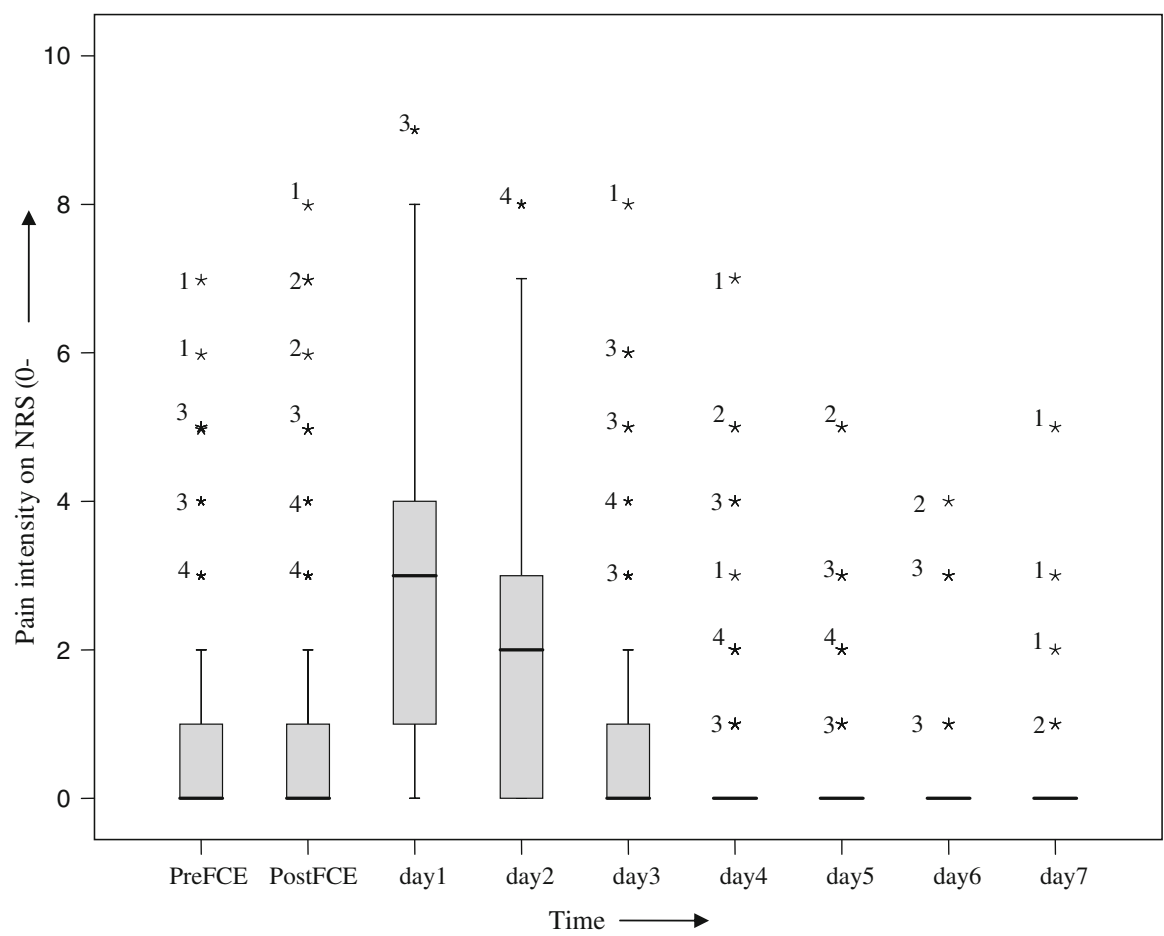

\begin{tabular}{lllllr}
\hline Scale & $\begin{array}{l}\text { Subjects } \\
\text { Mean (SD); } \\
n=197\end{array}$ & $\begin{array}{l}\text { Normative data } \\
\text { of Dutch population } \\
(n=1063)[22]\end{array}$ & $\begin{array}{l}\text { Group 1 } \\
\text { mean (SD); } \\
n=162\end{array}$ & $\begin{array}{l}\text { Group 2 } \\
\text { Mean (SD); } \\
n=35\end{array}$ & $t$-value $(P)$ \\
\hline Vitality & $66.0(13.0)$ & $67.4(19.9)$ & $67.0(12.2)$ & $62.0(15.3)$ & $2.1(0.04)$ \\
Mental health & $70.4(10.7)$ & $76.8(18.4)$ & $71.1(10.1)$ & $67.6(13.1)$ & $1.7(0.09)$ \\
Social functioning & $90.1(15.1)$ & $86.9(20.5)$ & $91.8(12.2)$ & $83.3(22.5)$ & $2.1(0.04)$ \\
General health perception & $75.5(16.5)$ & $72.7(22.7)$ & $76.7(15.9)$ & $70.3(18.1)$ & $2.1(0.04)$ \\
Pain & $91.6(12.2)$ & $79.5(25.6)$ & $92.1(12.4)$ & $89.3(11.4)$ & $1.2(0.22)$ \\
Role limitation (emotional) & $91.2(25.8)$ & $84.1(32.3)$ & $93.2(23.1)$ & $81.9(34.6)$ & $1.85(0.07)$ \\
Role limitation (physical) & $94.2(17.4)$ & $79.4(35.5)$ & $94.1(17.9)$ & $94.5(15.2)$ & $-0.1(0.90)$ \\
Physical functioning & $96.5(7.0)$ & $81.9(23.2)$ & $96.7(7.1)$ & $95.9(6.4)$ & $0.65(0.52)$ \\
Health change & $53.5(15.4)$ & $52.4(19.4)$ & $54.0(15.3)$ & $51.4(16.0)$ & $0.87(0.39)$
\end{tabular}

Table 5 Independent $t$-test and Mann-Whitney test of the differences of pain intensity and duration between patients with CLBP ( $n=54)$ [6] and healthy subjects $(n=197)$

\begin{tabular}{|c|c|c|c|c|c|c|c|c|}
\hline & \multicolumn{4}{|c|}{ Comparison of pain duration } & \multicolumn{4}{|c|}{ Comparison of pain intensity } \\
\hline & $\begin{array}{l}\text { Duration pain increase } \\
\text { mean days (SD) }\end{array}$ & $\begin{array}{l}\text { Mean } \\
\text { difference }\end{array}$ & $\begin{array}{l}t \text {-value } \\
(P)\end{array}$ & $95 \% \mathrm{CI}$ & $\begin{array}{l}\text { Pain decreased } \\
n(\%)\end{array}$ & $\begin{array}{l}\text { No difference } \\
n(\%)\end{array}$ & $\begin{array}{l}\text { Pain increased } \\
n(\%)\end{array}$ & $\mathrm{Z}(P)$ \\
\hline CLBP & $3.7(3.4)$ & 0.7 & $-1.2(0.23)$ & -1.95 to 4.81 & $2(4)$ & $11(21)$ & $41(76)$ & $-1.13(0.26)$ \\
\hline Healthy subjects & $3.0(2.5)$ & & & & $15(8)$ & $48(24)$ & $134(68)$ & \\
\hline
\end{tabular}

95\% CI: 95\% confidence interval

\section{Discussion}

The results of this study show that the pain response in healthy subjects followed a pattern which resembles normal exercise physiology [10]. The group of subjects in this study can be generalized to the Dutch population because personal characteristics such as gender, length, weight and health perception resemble the Dutch population (Tables 2 and 4). The three domains Pain, Physical Functioning and Role limitation (physical) of the RAND-36 however differ clinically from the Dutch population (Table 4). This may be due to the inclusion criteria of this study; only healthy 
working subjects between 20 and 60 years of age were included, who had no dysfunction of the musculoskeletal system at the time of FCE. There were 53 subjects who reported pain prior to the FCE while stating that they were without complaints when they signed informed consent. In total there were 35 subjects who reported a value over $2.5 \times \mathrm{IQR}$ above the median on pain intensity partly because they reported a pain response prior to the FCE. Post hoc analyses of personal characteristics reveal that 2 sub-groups may have been included in this study, namely a group who rated their pain over $2.5 \times \mathrm{IQR}$ above the median, and a group who rated their pain under $2.5 \times \mathrm{IQR}$ above the median. Table 4 illustrates that the group who rated their pain over $2.5 \times \mathrm{IQR}$ above the median scores lower on vitality, general health perception and social functioning but not on pain and physical functioning. When we take into consideration the point-prevalence of musculoskeletal pain in the Dutch population (53.9\%) than, of this population, $70 \%$ reports no limitation in daily life resulting from musculoskeletal pain [23]. This means there is a large number of persons in the Dutch population who do experience pain but are not restricted in daily life activities. The data of the current study may possibly have included a part of this group. Thus, with regards to pain status and self reported ADL functioning, the subjects of this study appear similar to the open Dutch population. Consequently, the general pattern and diversity of the pain response as seen in this study should be considered to be a normal response rather than an indication of injury. There were two subjects $(1 \%)$ in this study who reported an abnormal reaction. However, it remains unknown whether this may be expected in a normal population after intensive exercise. The 1-week incidence of neck and back pain, calculated by The Dutch National Institute for Public Health and the Environment (RIVM), of the Dutch population is $0.15 \%$ for men and $0.18 \%$ for women [24]. Data concerning the incidence of musculoskeletal complaints after intensive exercise such as an FCE is unavailable but is presumed to be higher.

The second goal of this study was to investigate whether the pain response of healthy subjects is different from the pain response of patients with CLBP. Earlier research of the pain response of patients with CLBP [6] reported a pain increase in $76 \%$ of the subjects, which lasted for a mean of 3.4 days after the FCE. In our study we found a symptom increase in $82 \%$ of all subjects and a normalization of pain to pre-FCE levels on the third day following the FCE (Fig. 2). Differences between our study and the patient study [6] were non significant for the pain intensity increase as well as for duration of the pain increase (Table 5). However some differences in study design must be taken into account before drawing such a conclusion. The first concerns the content of the FCE. Our study included an additional treadmill ergometer test which may have led to a difference in pain response. The second difference concerns the patient characteristics. There was a difference in male/ female distribution in both studies. Post hoc analyses show a significant gender difference of 1.3 on pain intensity measured by the PRQ on the first day following the FCE. Female subjects are slightly "statistically significant" reporting more pain. Other possible characteristics of subjects may have led to differences between the studies. This, however, is beyond the scope of this paper and will be reported separately. Overall it can be said that the pain response of healthy subjects in this study appear similar to patient data [6]. Additionally, former research to the Cal FPC and the ELC test showed similar results and demonstrated safety of these protocols $[4,5]$. These protocols however differed substantially from the protocol used in this study. The FPC and the ELC protocols are based on psychophysical principles in which a patient determines his/ her own acceptable maximum effort. The protocols used in this study are based on kinesiophysical principles in which the evaluator also determines maximal safe effort. Former research into differences between both the psychophysical and kinesiophysical approaches has found differences between outcomes [25]. It appears, however, that when concerning safety, both the psychophysical and the kinesiophysical evaluations can be administered safely.

A weakness of this study was that no correction was made for pain responses after different exercises besides the FCE or for pain prior to the FCE. This has not been done because causality is not always clear. For example, if a subject reports a pain intensity of 2 on the PRQ on the first day following the FCE and has an intensive exercise afterwards, he or she might report a pain intensity of 5 the day following. In this example it is unclear whether the response is causal to the FCE or to any activity besides the FCE. On the other hand, all responses were reported in this study and the real pain intensity following the FCE could, therefore, be an overestimation. A total of 53 subjects reported pain before the FCE and 57 subjects reported pain directly after the FCE. It is remarkable that on an average, subjects reported a higher level of pain before undergoing the FCE than 4 days following the FCE. A reason for this might be that subjects are focused on the severity of pain they feel before the FCE and/or that they are just reporting about the pain they think is causal to the FCE on the days following the FCE.

The NIOSH guidelines are safety guidelines for recommendation of safe lifting. Former research to the concurrent validity between the WorkWell FCE lifting task and the NIOSH Recommend Weight Lift showed significant differences between both safe lifting recommendations in patients with CLBP [7]. Patients lifted on average $15 \mathrm{~kg}$ more on the WorkWell FCE lifting task than on the NIOSH RWL. It was however unknown whether the lifting tasks in 
the FCE could be administered safely, because data is lacking with regards to normative data of healthy subjects and it was unknown whether the pain responses in patients with CLBP were considered abnormal or normal. The normative data in the current study is therefore additional to the question whether the FCE can be administered safely. This study indicates that an FCE can be administered safely if all safety procedures are followed.

In conclusion, the pain response of most healthy subjects (99\%) was interpreted as a normal physiological reaction of the musculoskeletal system after intensive exercise such as an FCE. $1 \%$ of the subjects reported an abnormal reaction. For a clinician the data from this study is of concern because it means that a pain response can be expected and considered normal after an FCE. Healthy workers and patients should be informed that a pain response can be expected and that this should in the vast majority of the cases be interpreted as a normal reaction of the musculoskeletal system after intensive exercise.

Acknowledgement This study was funded by the Stichting Instituut GAK, project number 2100304.

Open Access This article is distributed under the terms of the Creative Commons Attribution Noncommercial License which permits any noncommercial use, distribution, and reproduction in any medium, provided the original author(s) and source are credited.

\section{Appendix 1: Pain Response Questionnaire}

Pain Response Questionnaire

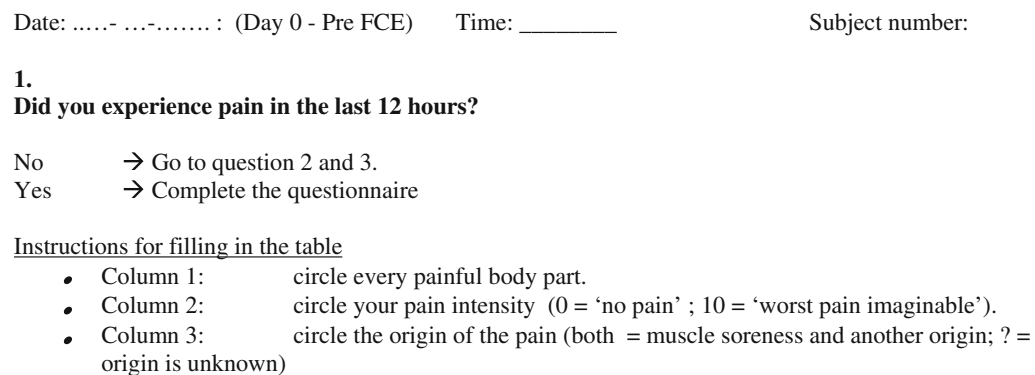

\begin{tabular}{|c|c|c|c|c|c|c|c|c|c|c|c|c|c|c|c|}
\hline \multirow{2}{*}{\begin{tabular}{|l} 
Column 1 \\
Body part \\
Neck \\
\end{tabular}} & \multicolumn{4}{|c|}{$0=$ 'no pain' } & \multicolumn{7}{|c|}{$\begin{array}{l}\text { Column } 2 \\
10=\text { 'Worst imaginable pain' }\end{array}$} & \multicolumn{4}{|c|}{$\begin{array}{c}\text { Column } 3 \\
\text { 'Origin of the pain' }\end{array}$} \\
\hline & 0 & 1 & 2 & 3 & 4 & 5 & 6 & 7 & 8 & 9 & 10 & Muscle soreness & other & both & $?$ \\
\hline Shoulder & 0 & 1 & 2 & 3 & 4 & 5 & 6 & 7 & 8 & 9 & 10 & Muscle soreness & other & both & $?$ \\
\hline Upper arm & 0 & 1 & 2 & 3 & 4 & 5 & 6 & 7 & 8 & 9 & 10 & Muscle soreness & other & both & $?$ \\
\hline Elbow & 0 & 1 & 2 & 3 & 4 & 5 & 6 & 7 & 8 & 9 & 10 & Muscle soreness & other & both & $?$ \\
\hline Under arm & 0 & 1 & 2 & 3 & 4 & 5 & 6 & 7 & 8 & 9 & 10 & Muscle soreness & other & both & $?$ \\
\hline Wrist & 0 & 1 & 2 & 3 & 4 & 5 & 6 & 7 & 8 & 9 & 10 & Muscle soreness & other & both & $?$ \\
\hline Hand & 0 & 1 & 2 & 3 & 4 & 5 & 6 & 7 & 8 & 9 & 10 & Muscle soreness & other & both & $?$ \\
\hline Chest & 0 & 1 & 2 & 3 & 4 & 5 & 6 & 7 & 8 & 9 & 10 & Muscle soreness & other & both & $?$ \\
\hline Upper back & 0 & 1 & 2 & 3 & 4 & 5 & 6 & 7 & 8 & 9 & 10 & Muscle soreness & other & both & $?$ \\
\hline Lower back & 0 & 1 & 2 & 3 & 4 & 5 & 6 & 7 & 8 & 9 & 10 & Muscle soreness & other & both & $?$ \\
\hline Belly & 0 & 1 & 2 & 3 & 4 & 5 & 6 & 7 & 8 & 9 & 10 & Muscle soreness & other & both & $?$ \\
\hline Buttocks & 0 & 1 & 2 & 3 & 4 & 5 & 6 & 7 & 8 & 9 & 10 & Muscle soreness & other & both & $?$ \\
\hline Upper leg & 0 & 1 & 2 & 3 & 4 & 5 & 6 & 7 & 8 & 9 & 10 & Muscle soreness & other & both & $?$ \\
\hline Knee & 0 & 1 & 2 & 3 & 4 & 5 & 6 & 7 & 8 & 9 & 10 & Muscle soreness & other & both & $?$ \\
\hline Lower leg & 0 & 1 & 2 & 3 & 4 & 5 & 6 & 7 & 8 & 9 & 10 & Muscle soreness & other & both & $?$ \\
\hline Ankle & 0 & 1 & 2 & 3 & 4 & 5 & 6 & 7 & 8 & 9 & 10 & Muscle soreness & other & both & $?$ \\
\hline Foot & 0 & 1 & 2 & 3 & 4 & 5 & 6 & 7 & 8 & 9 & 10 & Muscle soreness & other & both & $?$ \\
\hline Different: & 0 & & & 3 & 4 & 5 & 6 & 7 & 8 & 9 & 10 & Muscle soreness & other & both & $?$ \\
\hline
\end{tabular}

2.

Did you perform any heavy or unusual physical activity in the past 24 hours?

NO

YES $\quad \rightarrow \quad$ If yes, please describe the physical activity:

3.

Did you experience any other physical reactions which were not addressed yet?

NO

YES $\rightarrow \quad$ Namely ...

4.

Did you use any medication following the FCE?

NO

YES $\rightarrow \quad$ Name medication: 


\section{References}

1. Hart DL, Isernhagen SJ, Matheson LN. Guidelines for functional capacity evaluation of people with medical conditions. JOSPT. 1993;18(6):682-6.

2. Gouttebarge V, Wind H, Kuijer PPFM, Frings-Dresen MHW. A systematic review with reference to Blankenship System, Ergos Work Simulator, Ergo-kit and Isernhagen Work System. Int Arch Occup Environ Health. 2004;77:527-37.

3. Gibson L, Strong J. Safety issues in functional capacity evaluation: findings from a trial of a new approach for evaluating clients with chronic back pain. J Occup Rehabil. 2005;15(2): 237-51.

4. Matheson L, Mooney V, Grant J, Leggett S, Kenny K. Standardized evaluation of work capacity. J Musculoskeletal Rehab. 1998;6:249-6.

5. Matheson LN, Mooney V, Grant JE, Affleck M, Hall H, Melles T, Lichter RL, McIntosh G. A test to measure lift capacity of physically impaired adults. Part 1-Development and reliability testing. Spine. 1995;20(19):2119-29.

6. Reneman MF, Kuijer W, Brouwer S, Schiphorst Preuper HR, Groothoff JW, Geertzen JH, Dijkstra PU. Symptom increase following a functional capacity evaluation in patients with chronic low back pain: an explorative study of safety. J Occup Rehabil. 2006;16(2):197-205.

7. Kuijer W, Dijkstra PU, Brouwer S, Reneman MF, Groothoff JW, Geertzen JH. Safe lifting in patients with chronic low back pain: comparing FCE lifting task and NIOSH lifting guideline. J Occup Rehabil. 2006;16(4):579-89.

8. National Institute for Occupational Safety and Health. Applications manual for the revised NIOSH lifting equation. National Institute of Occupational Safety and Health; 1994.

9. Isernhagen SJ. Work injury, management and prevention. Gaithersburg, Maryland, USA: Aspen publishers, Inc; 1988.

10. Powers SK, Howley ET. Exercise physiology. Theory and application to fitness and performance. 4 ed. New York: McGraw-Hill; 2001.

11. Cheung K, Hume P, Maxwell L. Delayed onset muscle soreness: treatment strategies and performance factors. Sports Med. 2003;33(2):145-64.

12. Shephard RJ. PAR-Q, Canadian home fitness test and exercise screening alternatives. Sports Med. 1988;5(3):185-95.
13. Thomas S, Reading J, Shephard RJ. Revision of the Physical Activity Readiness Questionnaire (PAR-Q). Can J Sport Sci. 1992;17(4):338-345.

14. Matheson LN, Mooney V, Holmes D, Leggett S, Grant JE, Negri S, Holmes B. A test to measure lift capacity of physically impaired adults. Part 2-Reactivity in a patient sample. Spine. 1995;20(19):2130-34.

15. Borg G. Psychophysical scaling with applications in physical work and the perception of exertion. Scan J Work Environ Health. 1990;16(1):55-8.

16. Borg G. Borg's perceived exertion and pain scales. Campaign, IL, USA: Human Kinetics; 1998.

17. Reneman MF, Brouwer S, Meinema A, Dijkstra PU, Geertzen JH, Groothoff JW. Test-retest reliability of the Isernhagen work systems functional capacity evaluation in healthy adults. J Occup Rehabil. 2004;14(4):295-305.

18. Soer R, Gerrits EH, Reneman MF. Test-retest reliability of a WRULD functional capacity evaluation in healthy adults. Work. 2006;26(3):273-80.

19. Bruce RA. Exercise testing and training of apparently healthy individuals: a handbook for physicians. New York, USA: American Heart Association; 1972.

20. Williamson A, Hoggart B. A review of three commonly used pain rating scales. J Clin Nurs. 2005;14(7):798-804.

21. Reesink DD, Soer R, Reneman MF. Self-reported physical response after completing a functional capacity evaluation in healthy subject-a pilot study. Center for Movement Sciences, University of Groningen; 2006. Unpublished thesis.

22. Zee van der KI, Sanderman R. Het meten van de algemene gezondheidstoestand met de RAND-36. Article in Dutch. Noordelijk Centrum voor Gezondheidsvraagstukken. Rijksuniversiteit Groningen, The Netherlands. 1993. ISBN 90-72156-60-9.

23. Picavet HS, Schouten JS. Musculoskeletal pain in the Netherlands: prevalences, consequences and risk groups, the DMC(3)study. Pain 2003;102(1-2):167-78.

24. Poos MJJC, Gool van CH. Prevalentie, incidentie en sterfte naar leeftijd en geslacht. Article in Dutch. Nationaal Kompas Volksgezondheid version 3.10.1 2007. RIVM, Bilthoven, The Netherlands.

25. Soer R, Poels BJJ, Geertzen JHB, Reneman MF. A comparison of two lifting assessment approaches in patients with chronic low back pain. J Occup Rehabil. 2006;16:639-46. 